\title{
MTA1 promotes the invasion and migration of non-small cell lung cancer cells by downregulating miR-125b
}

\author{
Yiyi $\mathrm{Li}^{1 \dagger}$, Yilan Chao ${ }^{1 \dagger}$, Yuan Fang ${ }^{1 \dagger}$, Jian Wang ${ }^{1}$, Min Wang ${ }^{1}$, Hong Zhang ${ }^{1}$, Min Ying ${ }^{1}$, Xiaoxia Zhu ${ }^{1 *}$ \\ and Haofei Wang ${ }^{2^{*}}$
}

\begin{abstract}
Background: The metastasis-associated gene 1 (MTA1) has been identified as one critical regulator of tumor metastasis. Previously, we identified miR-125b as a downregualted miRNA in non-small cell lung cancer (NSCLC) cell line upon MTA1 depletion. However, the role of miR-125b and MTA1 in the regulation of NSCLC metastasis remains unclear.

Methods: Stable MTA1 knockdown NSCLC cell lines 95D and SPC-A-1 were established by transfection with MTA1 shRNA. The effects of MTA1 depletion on the expression of miR-125b and cell migration and invasion were examined by real-time PCR, wound healing and matrigel invasion assay.

Results: MTA1 knockdown led to the upregulation of miR-125b level in NSCLC cells. Furthermore, MTA1 knockdown reduced while miR-125b inhibitor enhanced cell migration and invasion of NSCLC cells. Notably, miR125b inhibitor antagonized MTA1 siRNA induced inhibition of cell migration and invasion.

Conclusion: MTA1 and miR-125b have antagonistic effects on the migration and invasion of NSCLC cells. The newly identified MTA1-miR-125b axis will help further elucidate the molecular mechanism of NSCLC progression and suggest that ectopic expression of miR-125b is a potentially new therapeutic regimen against NSCLC metastasis.
\end{abstract}

Keywords: miR-125b, MTA1, Non-small cell lung cancer, Metastasis

\section{Introduction}

Metastasis is the leading cause of failure in clinical treatment of malignant tumors including lung cancer. The metastasis-associated gene 1 (MTA1) has been identified as one critical regulator of the metastasis of many human cancers [1-4]. In our previous studies we deomnstrated that MTA1 promoted the metastasis of non-small cell lung cancer (NSCLC), and identified miR$125 \mathrm{~b}$ as a downregualted miRNA in NSCLC cell line upon MTA1 depletion [5,6]. However, the role of miR-

\footnotetext{
*Correspondence: zhuxx011@163.com; whf0001@163.com

${ }^{\dagger}$ Equal contributors

'Department of Radiation Oncology, Nanfang Hospital, Southern Medical University, Guangzhou, Guangdong 510515, China

${ }^{2}$ Department of Cardiothoracic Surgery, Nanfang Hospital, Southern Medical University, Guangzhou, Guangdong 510515, China
}

125b and MTA1 in the regulation of invasive phenotype of NSCLC cells remains unclear.

It has been shown that miR-125b level was significantly correlated with good prognosis of liver cancer [7]. miR-125b was deregulated in lung cancer, oral squamous cell carcinoma, prostate cancer and pancreatic cancer [8-11]. However, controversial properties of miR-125b have been reported in different types of cancer. In human invasive breast cancer, miR-125b functioned as a tumor suppressor by regulating ETS1 proto-oncogene [12]. In addition, miR-125b was underexpressed in metastatic hepatocellular carcinoma (HCC) and inhibited HCC cell migration and invasion by directly targeting oncogene LIN28B2 [13,14]. In contrast, exogenous miR$125 \mathrm{~b}$ expression increased the migration of type I endometrial carcinoma cell line [15]. Moreover, miR-125b was proposed to function as a metastasis promoter

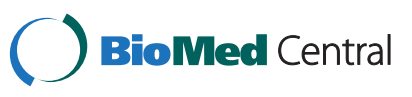

(c) 2013 Li et al.; licensee BioMed Central Ltd. This is an Open Access article distributed under the terms of the Creative Commons Attribution License (http://creativecommons.org/licenses/by/2.0), which permits unrestricted use, distribution, and reproduction in any medium, provided the original work is properly cited. 
through targeting STARD13 in breast cancer cells [16]. These data suggest that miR-125b may perform different regulatory functions on tumor progression in a cellular context-dependent manner.

In the present study, we established two MTA1knockdown NSCLC cell lines using stable transfection technology and validated the effects of MTA1 depletion on the expression of miR-125b. Using these cell lines we further examined the function of miR-125b in the regulatuion of cell migration and the interaction between miR-125b and MTA1. Our resutls showed that miR-125b acted as a metastasis suppressor in vitro and reversed the stimulatous effect of MTA1 on the migration of NSCLC cell lines.

\section{Methods}

\section{Cell culture}

Human non-small lung cancer cell lines 95D and SPC-A-1 were purchased from Shanghai Cell Bank of Chinese Academy of Science (Shanghai, China). Cells were cultured in RPMI 1640 medium (Invitrogen, Carlsbad, CA) supplemented with $10 \%$ fetal calf serum at $37^{\circ} \mathrm{C}$ in a humidified atmosphere containing $5 \% \mathrm{CO}_{2}$.

\section{Transient transfection}

miR-125b-inhibitor (5'-UCACAAGUUAGGGUCUCAG GGA-3') and nonspecific control miRNA (NC, 5' -CAG UACUUUUGUGUAGUACAA-3') were designed based on miRbase Database (www.miRbase.org) and synthesized by Genepharma (Shanghai, China). Cells were seeded $\left(1.6 \times 10^{4} /\right.$ well $)$ onto 96 -well plate $18-20 \mathrm{~h}$ before transfection. Anti-miR-125b or NC was added to each well. After $6 \mathrm{~h}$ incubation at $37^{\circ} \mathrm{C}$ and $5 \% \mathrm{CO}_{2}$, the medium was replaced with fresh culture medium. The cells were harvested at $48 \mathrm{~h}$ post transfection.

\section{Establishment of stable cell line}

Cells were transfected with $3 \mu \mathrm{g}$ of plasmids (pLVTHMMTA1-si, or pLVTHM-CTL-si) which were constructed in previous study [6], or empty pLVTHM vector using Lipofectamine2000 (Invitrogen, Carlsbad, CA) according to the manufacturer's protocol, then selected for the resistant to neomycin. The stable resistant cell lines were selected and named as 95D (or SPC-A-1)/MTA1-si, 95D (or SPC-A-1)/ CTL-si, and 95D (or SPC-A-1)/NC, respectively.

\section{Quantitative real-time PCR}

Total RNA was extracted from the cells with Trizol reagent (Invitrogen) following the manufacturer's instruction. Quantitative real-time PCR for miR-125b or MTA1 mRNA was performed as described previously [6]. For miR-125b quantification, U6 small nuclear RNA (U6 snRNA) was used as internal control. The primers sequences were as follows: hsa-miR-125b forward: GGCAACCTTGCGACTATAACCA, reverse: GTTTCCT CTCCCTGAGACCCTA; U6 snRNA forward: CTCGCTT CGGCAGCACATATACT, reverse ACGCTTCACGAAT TTGCGTGTC. The relative quantification of expression levels was calculated using the $2^{-\Delta \Delta \mathrm{Ct}}$ method.

\section{Western blot analysis}

Total protein was extracted from the cells using RIPA kit (Pierce, USA). Protein concentrations of the supernatants were determined using BCA method. Equal amounts of proteins were separated by SDS-PAGE and transferred into nitrocellulose membranes, which were incubated with primary antibodies against MTA1 (1:1500; Abcam, Cambridge, MA, USA) and $\beta$-Actin (1:1000; Santa Cruz Biotech, Santa Cruz, CA, USA) at $4^{\circ} \mathrm{C}$ overnight. The membranes were washed three times with TBST and incubated with peroxidase conjugated goat anti-rabbit IgG secondary antibody (1:1000, Santa Cruz Biotech, Santa Cruz, CA, USA) for $1 \mathrm{~h}$ at room temperature. Finally, the membranes were washed three times with TBST and visualized using Western Blotting Luminol Reagent (Santa Cruz Biotech, Santa Cruz, CA, USA) according to the manufacturer's instruction.

\section{Wound healing assay}

Cells were seeded into six-well plate and grown to confluence. Wound was created by scraping confluent cell monolayers with a pipette tip. The cells were allowed to migrate for $48 \mathrm{~h}$. At $0 \mathrm{~h}$ and $48 \mathrm{~h}$ after scratching, images were taken under the inverted microscope to assess the ability of the cells to migrate into the wound area.

\section{Cell invasion assay}

$5 \times 10^{4}$ cells in serum-free media were seeded into the upper chambers of a 24-well BioCoat Matrigel invasion chamber (BD Bioscience, Bedford, MA, USA). Medium with $10 \% \mathrm{FBS}$ was added to the lower chambers as a chemoattractant. After $24 \mathrm{~h}$ of incubation, cells that invaded through the membrane filter were fixed and stained with H\&E. The number of invading cells was counted under fluorescence microscope in five random high power fields.

\section{Statistical analysis}

All experiments were repeated independently a minimum of three times, and the results were expressed as the mean values \pm standard deviation. The differences between groups were analyzed by two-tailed unpaired Student's $t$ test. A value of $\mathrm{p}<0.05$ was considered to indicate statistical significance. 


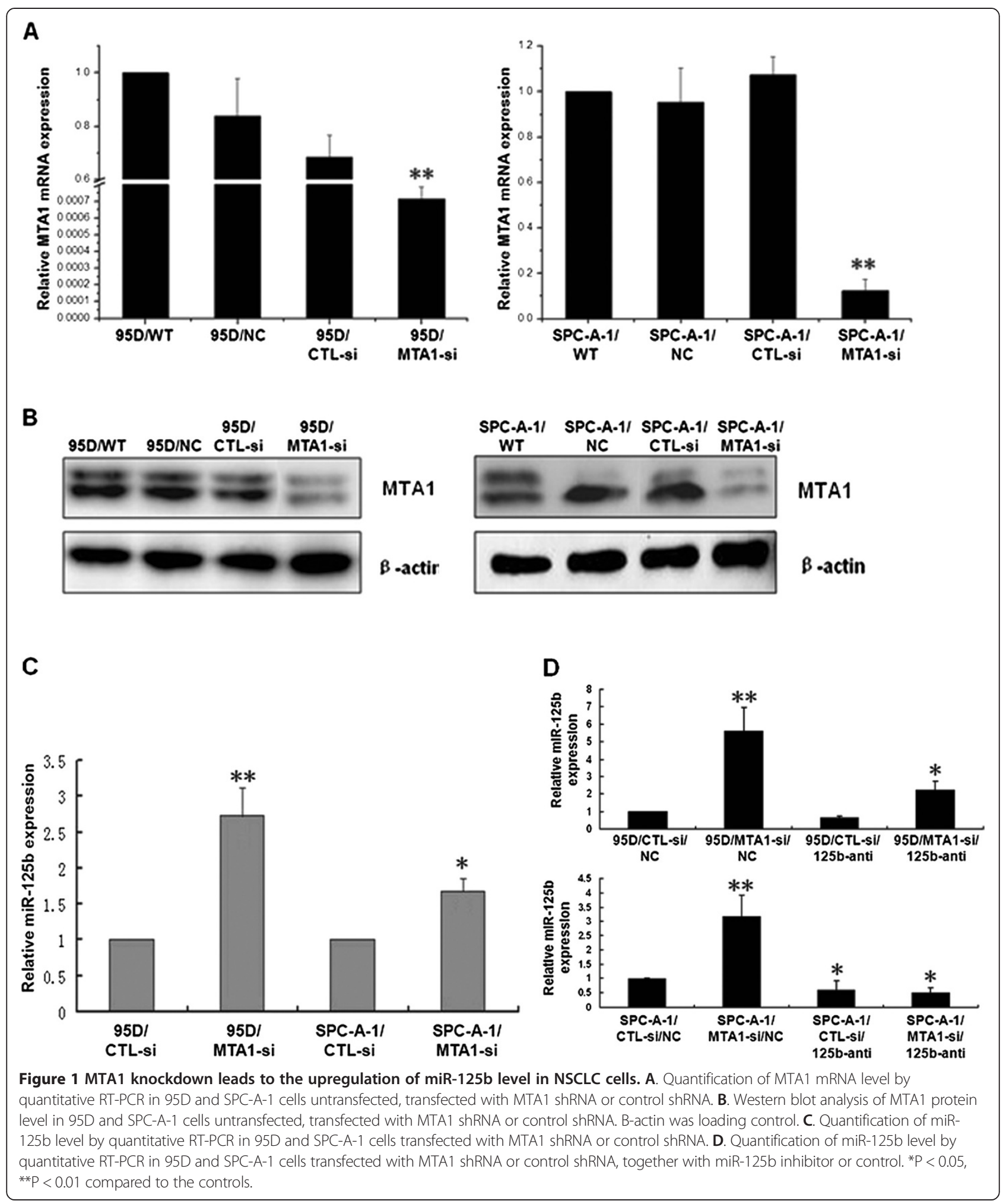




\section{Results}

MTA1 knockdown leads to the upregulation of miR-125b level in NSCLC cells

First we established 95D and SPC-A-1 cell lines with stable knockdown of MTA1 by transfecting the cells with MTA1 shRNA. The knockdown efficiency was confirmed by qRT-PCR and Western blot analysis.
Compared to the control cell lines, the expression of MTA1 mRNA and protein was significantly reduced in 95D and SPC-A-1 cells transfected with pLVTHMMTA1-si plasmid (Figure 1A, B).

Next we detected miR-125b level in the established cell lines. The results showed that miR-125b level was 2.75 and 1.67-fold higher in 95D/MTA1-si and SPC-

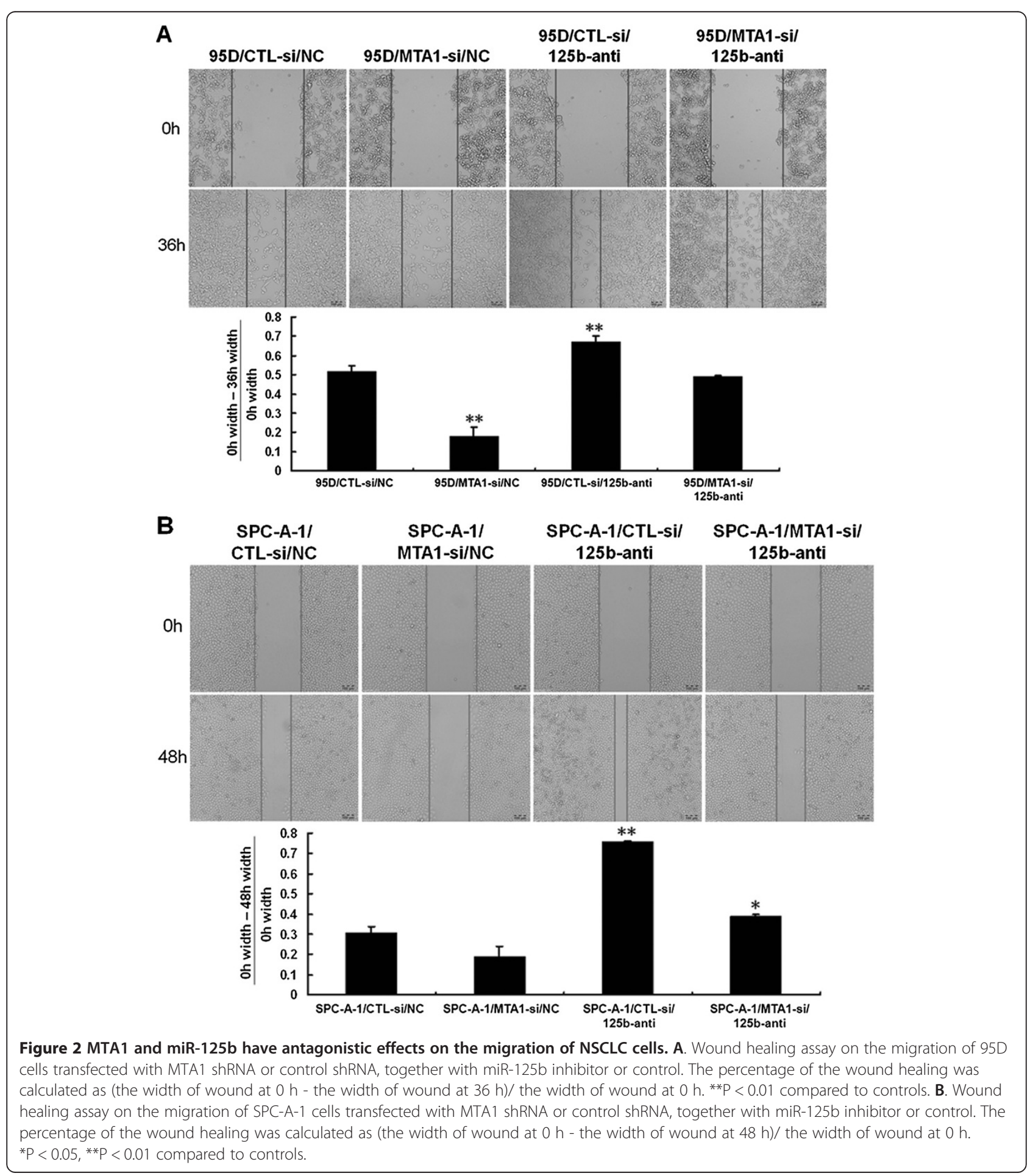


A-1/MTA1-si cells, compared to the control 95D and SPC-A-1 cells, respectively (Figure 1C). To confirm the negative correlation between MTA1 and miR-125b in NSCLC cells, we transfected miR-125b-inhibitor or nonspecific control miRNA (NC) into 95D and SPC-A-1 cells. qRT-PCR analysis showed that miR-125b-inhibitor decreased the expression of miR-125b in 95D/CTL-si and SPC-A-1/CTL-si cells only by 30 percent, but it significantly reduced miR-125b expression in 95D/MTA1si and SPC-A-1/MTA1-si cells (Figure 1D). These data suggest that MTA1 knockdown leads to the upregulation of miR-125b level in NSCLC cells.

MTA1 and miR-125b have antagonistic effects on the migration and invasion of NSCLC cells

Next we investigated the antagonistic effects of MTA1 and MiR-125b on the migration and invasion of NSCLC cells. Wound healing assay showed that in 95D cells, knockdown of MTA1 led to reduced cell migration. However, cell migration was increased in 95D cells treated with miR-125b inhibitor. Moreover, the migration of cells treated with both MTA1 shRNA and miR125b inhibitor was similar to control cells (Figure 2A).
Similar results were observed for the migration of SPCA-1 cells (Figure 2B). These data demonstrate that MTA1 promotes while miR-125b inhibits NSCLC cell migration and indicate that MTA1 may promote cell migration via the downregulation of miR-125b.

Matrigel invasion assay showed that in 95D cells, knockdown of MTA1 led to reduced cell invasion. However, cell invasion was increased in 95D cells treated with miR-125b inhibitor. Moreover, the invasion of cells treated with both MTA1 shRNA and miR-125b inhibitor was similar to control cells (Figure 3A). Similar results were observed for the invasion of SPC-A-1 cells (Figure 3B). These data demonstrate that MTA1 promotes while miR-125b inhibits NSCLC cell invasion and indicate that MTA1 may promote cell invasion via the downregulation of $\mathrm{miR}-125 \mathrm{~b}$.

\section{Discussion}

Recent studies have demonstrated the crucial role of miR-125b in tumorigenesis and metastasis [17-20]. Nevertheless, the role of miR-125b in lung cancer remains controversial. chr11q23-24 and chr21q11-21 are the region in which miR-125b-1 and miR-125b-2 are

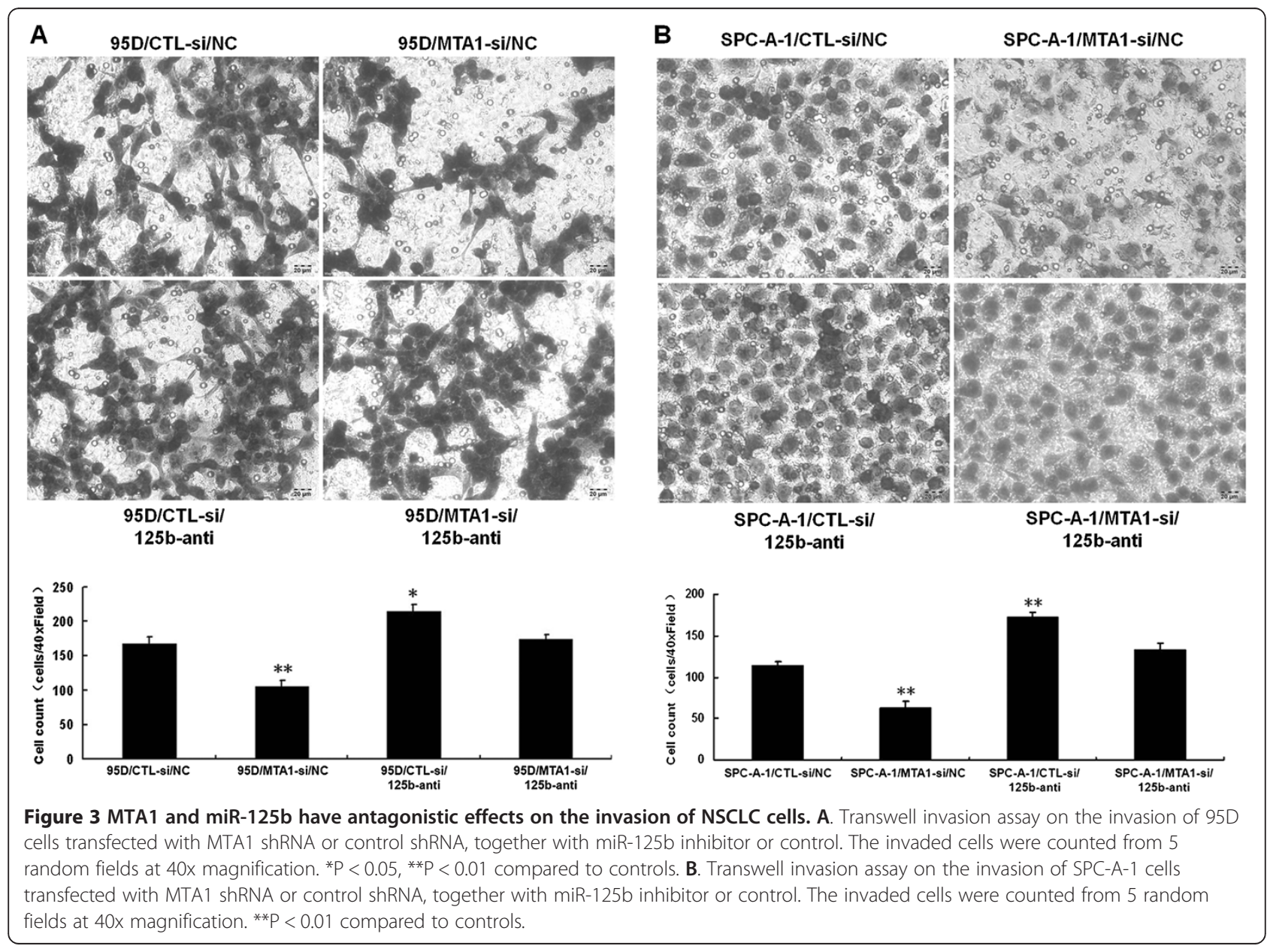


located, respectively, and they are frequently deleted in patients with lung cancer, indicating that miR-125b may function as a tumor suppressor in lung cancer $[8,21]$. However, miR-125b exhibited higher expression level in non-responsive patients with cisplatin-based chemotherapy [22]. Furthermore, the high level of miR-125b was significantly correlated with poor patient survival $[22,23]$. These data suggest that miR-125b may act as an oncogene in lung cancer.

In the present study, by cell biological analysis we demonstrated that inhibition of miR-125b promoted the migration and invasion of NSCLC cells, providing some evidence that miR-125b could serve as a tumor suppressor in the metastasis of NSCLC in vitro. The upstream regulators of miR-125b expression remain to be identified. Recently Liu et al. reported that STAT3 could promote the transcription of miR-125b in human osteosarcoma cells [24]. In addition, CDX2, a homeobox transcription factor, has been recently shown to bind to the promoter region of miR-125b and activate its transcription in malignant myeloid cells [25]. By microarray analysis, we previously found that miR-125b was significantly upregulated in MTA1 knockdown NSCLC cells [6]. In this study, we verified that endogenous expression of miR-125b increased after the depletion of MTA1 in two NSCLC cell lines, suggesting that miR-125b is regulated by MTA1 at the level of transcription. Furthermore, we found that the inhibition of miR125b could rescue the suppressive effects of MTA1 silencing on NSCLC cell migration and invasion. These results demonstrate for the first time that miR-125b is a functional target of MTA1 in lung cancer cells and suggest that ectopic expression of miR-125b is a promising strategy to counteract the promotion of tumor progression by MTA1.

It is known that MTA1, which is an integral part of nucleosome remodeling and deacetylation (NuRD) complexes, represses the transcription of target genes by recruiting histone deacetylases onto the promoter regions of target genes and inducing histone deacetylation [25]. Further studies are needed to elucidate the mechanism by which MTA1 downregulates the transcription of miR-125b in lung cancer cells.

\section{Conclusions}

In summary, we found that the expression of MTA1 and miR-125b is negatively correlated in lung cancer cells and they have antagonistic effects on the migration and invasion of NSCLC cells. The newly identified MTA1miR-125b axis will help further elucidate the molecular mechanism of NSCLC progression and suggest that ectopic expression of miR-125b is a potentially new therapeutic regimen against NSCLC metastasis.

\section{Competing interests}

The authors declare that they have no competing interests.

\section{Authors' contributions}

$Y L, Y C, Y F, J W, M W$ performed most of the experiments. HW and $X Z$ designed the study. $\mathrm{HZ}$ and MY performed statistical analysis. XZ supervised the study and wrote the manuscript. All authors read and approved the final manuscript.

\section{Acknowledgement}

This study was supported by grants from National Natural Science Foundation of China (No. 81001047/H1615), Educational Commission of Guangdong Province (No. LYM09037), Science and technology projects in Guangdong Province (No. 2012B031800127), and Natural Science Foundation of Guangdong Province (No. 9151051501000035).

Received: 10 May 2013 Accepted: 21 May 2013

Published: 29 May 2013

\section{References}

1. Jiang $Q$, Zhang $H$, Zhang P: ShRNA-mediated gene silencing of MTA1 influenced on protein expression of ER alpha, MMP-9, CyclinD1 and invasiveness, proliferation in breast cancer cell lines MDA-MB-231 and MCF-7 in vitro. J Exp Clin Cancer Res 2011, 30:60.

2. Wang H, Fan L, Wei J, Weng Y, Zhou L, Shi Y, Zhou W, Ma D, Wang C: Akt mediates metastasis-associated gene 1 (MTA1) regulating the expression of E-cadherin and promoting the invasiveness of prostate cancer cells. PLoS One 2012, 7(12):e46888.

3. Zhou H, Xu X, Xun Q, Yu D, Ling J, Guo F, Yan Y, Shi J, Hu Y: microRNA-30c negatively regulates endometrial cancer cells by targeting metastasisassociated gene-1. Oncol Rep 2012, 27(3):807-812.

4. Marzook H, Li DQ, Nair VS, Mudvari P, Reddy SD, Pakala SB, Santhoshkumar TR, Pillai MR, Kumar R: Metastasis-associated protein 1 drives tumor cell migration and invasion through transcriptional repression of RING finger protein 144A. J Biol Chem 2012, 287(8):5615-5626.

5. Zhu X, Guo Y, Li X, Ding Y, Chen L: Metastasis-Associated Protein 1 Nuclear Expression is Associated with Tumor Progression and Clinical Outcome in Patients with Non-small Cell Lung Cancer. J Thorac Oncol 2010, 5:1159-1166.

6. Zhu X, Zhang X, Wang H, Song Q, Zhang G, Yang L, Geng J, Li X, Yuan Y, Chen L: MTA1 gene silencing inhibits invasion and alters the microRNA expression profile of human lung cancer cells. Oncol Rep 2012, 28:218-224

7. Li W, Xie L, He X, Li J, Tu K, Wei L, Wu J, Guo Y, Ma X, Zhang P, Pan Z, Hu X, Zhao Y, Xie H, Jiang G, Chen T, Wang J, Zheng S, Cheng J, Wan D, Yang S, Li Y, GU J: Diagnostic and prognostic implications of microRNAs in human hepatocellular carcinoma. Int J Cancer 2008, 123:1616-1622.

8. Yamada H, Yanagisawa K, Tokumaru S, Taguchi A, Nimura Y, Osada H, Nagino M, Takahashi T: Detailed characterization of a homozygously deleted region corresponding to a candidate tumor suppressor locus at 21q11-21 in human lung cancer. Genes Chromosomes Cancer 2008, 47:810-818.

9. Henson BJ, Bhattacharjee S, O'Dee DM, Feingold E, Gollin SM: Decreased expression of miR-125b and miR-100 in oral cancer cells contributes to malignancy. Genes Chromosomes Cancer 2009, 48:569-582.

10. Schaefer A, Jung M, Mollenkopf HJ, Wagner I, Stephan C, Jentzmik F, Miller K, Lein M, Kristiansen $G$, Jung K: Diagnostic and prognostic implications of microRNA profiling in prostate carcinoma. Int J Cancer 2010, 126:1166-1176.

11. Bloomston M, Frankel WL, Petrocca F, Volinia S, Alder H, Hagan JP, Liu CG, Bhatt D, Taccioli C, Croce CM: MicroRNA expression patterns to differentiate pancreatic adenocarcinoma from normal pancreas and chronic pancreatitis. JAMA 2007, 297:1901-1908.

12. Zhang $Y$, Yan LX, Wu QN, Du ZM, Chen J, Liao DZ, Huang MY, Hou JH, Wu QL, Zeng MS, Huang WL, Zeng YX, Shao JY: miR-125b is methylated and functions as a tumor suppressor by regulating the ETS1 proto-oncogene in human invasive breast cancer. Cancer Res 2011, 71:3552-3562.

13. Budhu A, Jia HL, Forgues M, Liu CG, Goldstein D, Lam A, Zanetti KA, Ye QH, Qin LX, Croce CM, Tang ZY, Wang XW: Identification of metastasis-related microRNAs in hepatocellular carcinoma. Hepatology 2008, 47:897-907.

14. Liang L, Wong CM, Ying Q, Fan DN, Huang S, Ding J, Yao J, Yan M, Li J, Yao $\mathrm{M}, \mathrm{Ng}$ IO, He X: MicroRNA-125b suppressesed human liver cancer cell proliferation and metastasis by directly targeting oncogene LIN28B2. Hepatology 2010, 52:1731-1740. 
15. Jiang $F$, Liu $T$, He $Y$, Yan $Q$, Chen $X$, Wang $H$, Wan X: MiR-125b promotes proliferation and migration of type II endometrial carcinoma cells through targeting TP53INP1 tumor suppressor in vitro and in vivo. BMC Cancer 2011, 11:425.

16. Tang F, Zhang R, He Y, Zou M, Guo L, Xi T: MicroRNA-125b induces metastasis by targeting STARD13 in MCF-7 and MDA-MB-231 breast cancer cells. PLoS One 2012, 7:e35435.

17. Kappelmann M, Kuphal S, Meister G, Vardimon L, Bosserhoff AK: MicroRNA miR-125b controls melanoma progression by direct regulation of c-Jun protein expression. Oncogene 2012. doi:10.1038/onc.2012.307 [Epub ahead of print].

18. Ngo-Yin Fan D, Ho-Ching Tsang F, Hoi-Kam Tam A, Leung-Kuen Au S, Chak-Lui Wong C, Wei L, Man-Fong Lee J, He X, Oi-Lin Ng I, Wong CM: Histone lysine methyltransferase, suppressor of variegation 3-9 homolog 1 , promotes hepatocellular carcinoma progression and is negatively regulated by microRNA-125b. Hepatology 2013, 57(2):637-47.

19. Xu N, Zhang L, Meisgen F, Harada M, Heilborn J, Homey B, Grandér D, Ståhle M, Sonkoly E, Pivarcsi A: MicroRNA-125b down-regulates matrix metallopeptidase 13 and inhibits cutaneous squamous cell carcinoma cell proliferation, migration, and invasion. J Biol Chem 2012, 287(35):29899-908.

20. Liu LH, Li H, Li JP, Zhong H, Zhang HC, Chen J: Xiao T.miR-125b suppresses the proliferation and migration of osteosarcoma cells through down-regulation of STAT3. Biochem Biophys Res Commun 2011, 416(1-2):31-8

21. Martin ES, Cesari R, Pentimalli F, Yoder K, Fishel R, Himelstein AL, Martin SE, Godwin AK, Negrini M, Croce CM: The BCSC-1 locus at chromosome 11q23-q24 is a candidate tumor suppressor gene. Proc Natl Acad Sci USA 2003, 100(20):11517-22.

22. Cui EH, Li HJ, Hua F, Wang B, Mao W, Feng XR, Li JY, Wang X: Serum microRNA $125 \mathrm{~b}$ as a diagnostic or prognostic biomarker for advanced NSCLC patients receiving cisplatin-based chemotherapy. Acta Pharmacol $\sin$ 2013, 34(2):309-13.

23. Yuxia $M$, Zhennan $T$, Wei Z: Circulating miR-125b is a novel biomarker for screening non-small-cell lung cancer and predicts poor prognosis. $J$ Cancer Res Clin Oncol 2012, 138(12):2045-50.

24. Lin KY, Zhang XJ, Feng DD, Zhang H, Zeng CW, Han BW, Zhou AD, Qu LH Xu L, Chen YQ: miR-125b, a target of CDX2, regulates cell differentiation through repression of the core binding factor in hematopoietic malignancies. J Biol Chem 2011, 286(44):38253-63.

25. Toh Y, Kuninaka S, Endo K, Oshiro T, Ikeda Y, Nakashima H, Baba H, Kohnoe S, Okamura T, Nicolson GL, Sugimachi K: Molecular analysis of a candidate metastasis-associated gene, MTA1: possible interaction with histone deacetylase 1. J Exp Clin Cancer Res 2000, 19:105-11.

doi:10.1186/1756-9966-32-33

Cite this article as: $L i$ et al: MTA1 promotes the invasion and migration of non-small cell lung cancer cells by downregulating miR-125b. Journal of Experimental \& Clinical Cancer Research 2013 32:33.

\section{Submit your next manuscript to BioMed Central and take full advantage of:}

- Convenient online submission

- Thorough peer review

- No space constraints or color figure charges

- Immediate publication on acceptance

- Inclusion in PubMed, CAS, Scopus and Google Scholar

- Research which is freely available for redistribution

Submit your manuscript at www.biomedcentral.com/submit
Ciomed Central 